\title{
The selective neuronal nitric oxide synthase inhibitor 7-nitroindazole has acute analgesic but not cumulative effects in a rat model of peripheral neuropathy
}

\author{
This article was published in the following Dove Press journal: \\ Journal of Pain Research \\ | April 201। \\ Number of times this article has been viewed
}

\section{Liliane J Dableh \\ James L Henry}

Department of Psychiatry and

Behavioural Neurosciences, McMaster

University, Hamilton, Ontario, Canada
Correspondence: James L Henry Department of Psychiatry and Behavioural Neurosciences, McMaster University, Health Sciences Centre, Room 4N35, I 200 Main Street West, Hamilton, Ontario, L8N 3Z5, Canada Tel + I 9055259140

Fax + I 9055228844

Email jhenry@mcmaster.ca

\begin{abstract}
Chronic neuropathic pain that may arise from various nerve injuries or insults remains notoriously difficult to manage. The neuronal isoform of the enzyme nitric oxide synthase (nNOS) has been shown to be involved in the spinal transmission of nociception in animal models of chronic pain. The aim of this study is to evaluate the effect of single dose and repeated administration of a selective nNOS inhibitor. Rats were unilaterally implanted with a 2-mm polyethylene cuff around the sciatic nerve. Paw withdrawal thresholds were measured using von Frey filament stimulation. Rats were given 10, 20, or $30 \mathrm{mg} / \mathrm{kg}$ of 7-nitroindazole (7-NI), or vehicle, on days 2, 5, and 7 after model induction, respectively. Paw withdrawal thresholds were measured before and at 30 and $60 \mathrm{~min}$ after injection. 7-NI significantly increased paw withdrawal thresholds at $60 \mathrm{~min}$ at the 20 and $30 \mathrm{mg} / \mathrm{kg}$ dosages. In the second part of this study, rats were given $20 \mathrm{mg} / \mathrm{kg}$ 7-NI daily for five days starting immediately after cuff implantation (days 0 to 4 ), and the cuff was removed on day 4 . Withdrawal thresholds were measured intermittently over a 24-day observation period. No differences in withdrawal thresholds were observed between drug and vehicle-treated rats. Therefore, early and repeated administration of 7-NI did not affect the development or progression of the model. In conclusion, inhibition of nNOS had an analgesic but not a pre-emptive effect in this model of peripheral neuropathic pain.
\end{abstract}

Keywords: neuronal nitric oxide synthase, nitric oxide, 7-nitroindazole, neuropathic pain, peripheral nerve injury, nociception

\section{Introduction}

Physiological pain clearly serves an important protective function. However, when pain lasts more than 3 months, it is classified as chronic pain, and pathological mechanisms may be involved. The International Association for the Study of Pain (IASP) has recently refined the definition of neuropathic pain as "pain arising as a direct consequence of a lesion or disease affecting the somatosensory system". ${ }^{1}$ Therefore, neuropathic pain may result from a range of causes, including trauma, infection, ischemia, and toxicity. Nitric oxide has been identified as one of the many agents involved in neuropathic pain.

Nitric oxide is a gaseous neurotransmitter in the central nervous system (CNS) and the peripheral nervous system (PNS), and is able to diffuse across the cell membrane. ${ }^{2}$ Nitric oxide is involved in several physiological processes including smooth muscle relaxation, inflammation, vasodilation, neurogenesis, synaptic plasticity, long-term potentiation, and nociceptive transmission. ${ }^{2,3}$ The enzyme nitric oxide synthase (NOS) 
catalyzes the production of nitric oxide from L-arginine and oxygen, and different isoforms of the enzyme exist in different tissues. Nitric oxide is constitutively produced by neuronal NOS (nNOS) and endothelial NOS (eNOS) in a calcium-dependent manner, and is also formed by an inducible form of the enzyme (iNOS), which may have detrimental effects on the cell. ${ }^{2-4}$ Neuronal NOS is found in both the CNS and PNS.

Neuronal NOS has been specifically localized to spinal cord dorsal horn neurons and dorsal root ganglia (DRG) cells, and is upregulated in conditions of inflammatory and neurogenic pain. ${ }^{3-5}$ Synthesis of nitric oxide in the nociceptive pathway is thought to be the result of activation of the N-methyl-D-aspartate (NMDA) receptor. Activation of peripheral nociceptive neurons results in the presynaptic release of glutamate, as well as various neuromodulators. Sufficient depolarization of the postsynaptic membrane will activate NMDA receptors allowing an influx of $\mathrm{Ca}^{2+}$ into the dorsal horn neurons, which leads to, among other events, activation of $\mathrm{nNOS}$ and synthesis of nitric oxide. ${ }^{2}$ Nitric oxide may act at the postsynaptic neuron, or act as a retrograde transmitter at the presynaptic neuron, as well as interneurons and glial cells. ${ }^{2}$ Nitric oxide can facilitate nociceptive transmission through its downstream targets. ${ }^{4}$

Several lines of evidence have shown that the synthesis of nitric oxide may play an important role in neuropathic pain following nerve injury. Experimentally it has been shown that chronic constriction injury (CCI) causes increased nNOSimmunoreactivity in the L4 to L6 DRG cells and dorsal horn neurons ipsilateral to nerve injury, ${ }^{6}$ and also in the sciatic nerve epineurium. ${ }^{7}$ Increases in nNOS protein and mRNA were also observed following peripheral axotomy in the DRG and trigeminal ganglion. ${ }^{8}$ An electrophysiological study found that administration of the nonselective NOS inhibitor $\mathrm{N}^{\omega}$-nitro-L-arginine methyl ester (L-NAME) attenuated ongoing discharges in the DRG in a sciatic nerve axotomy model. ${ }^{9}$ Finally, behavioral studies have shown that L-NAME and selective nNOS inhibitors relieve pain hypersensitivity in various nerve injury models, ${ }^{10-12}$ while nitric oxide precursors and donors enhance hypersensitivity. ${ }^{13}$

The objective of the present study is to determine whether nitric oxide is involved in the maintenance or the development of a modified version of the sciatic cuff model ${ }^{14}$ of neuropathic pain. The immediate effect of nNOS inhibition was assessed in cuff-implanted rats. Also, the effect of early and repeated administration of the nNOS inhibitor on the development of the model was assessed over 24 days.

\section{Materials and methods}

\section{Animals}

Male Sprague-Dawley rats (Charles River, Quebec, Canada) were housed in pairs and maintained on a 12-hour light cycle, with food and water available ad libitum. All procedures complied with the Guidelines for the care and use of experimental animals, Volumes I and II, of the Canadian Council on Animal Care. All procedures were also approved by the Animal Research Ethics Board (McMaster University, Hamilton, Ontario, Canada).

\section{Drug}

For the single dose study, 7-nitroindazole (7-NI; Lancaster Synthesis, Windham, $\mathrm{NH}$ ) was dissolved in $75 \%$ dimethyl sulfoxide (DMSO; Sigma-Aldrich, St. Louis, MO) in saline, and given at dosages of 10,20 , or $30 \mathrm{mg} / \mathrm{kg}$. 7-NI and the vehicle were administered intraperitoneally (IP) at a volume of $0.1 \mathrm{~mL} / 100 \mathrm{~g}$ body weight. For the repeated administration study, 7-NI was dissolved in DMSO, and given at a dosage of $20 \mathrm{mg} / \mathrm{kg}$. 7-NI and the vehicle were administered IP at half the injection volume above $(0.05 \mathrm{~mL} / 100 \mathrm{~g}$ body weight). The drug solution was prepared fresh on each day before injection.

\section{Surgical preparations}

Cuff implantation

The method of sciatic nerve constriction is based on that described by Mosconi and Kruger. ${ }^{14}$ Rats were anesthetized with a combination of ketamine (Ketalean; $5 \mathrm{mg} / 100 \mathrm{~g}$; Bimeda-MTC Animal Health Inc, Cambridge, Ontario, Canada), xylazine (Rompun; $0.5 \mathrm{mg} / 100 \mathrm{~g}$; Bayer HealthCare, Toronto, Ontario, Canada), and acepromazine (Atravet; $0.1 \mathrm{mg} / 100 \mathrm{~g}$; Ayerst Veterinary Laboratories, Guelph, Ontario, Canada) by IP injection. The left sciatic nerve was exposed after blunt dissection of overlying muscle and freed from surrounding tissue. A cuff made of a $2 \mathrm{~mm}$ segment of polyethylene (PE-90) tubing (Intramedic PE-90, Clay Adams, Division of Becton Dickinson, Parsippany, NJ) slit longitudinally was fitted around the nerve. Subsequently the muscle was sutured, and the skin closed using suture clips. Antibiotic ointment (Furacin; nitrofurazone $0.2 \%$; Vetoquinol N-A Inc, Lavaltrie, Quebec, Canada) was applied over the wound, and $0.03 \mathrm{~mL}$ of antibiotic (Novo-Trimel; $40 \mathrm{mg} / \mathrm{mL}$ sulfamethoxazole and $8 \mathrm{mg} / \mathrm{mL}$ trimethoprim; Novopharm, Toronto, Ontario, Canada) was injected subcutaneously (SC). Animals were given $1 \mathrm{~mL}$ saline $\mathrm{SC}$, ocular lubricant, and placed under a heating lamp until they recovered from the anesthetic and then returned to their home cage. 


\section{Cuff removal}

Animals were anesthetized and the sciatic nerve was exposed as described above. The cuff was located and removed using a fine forceps while care was taken not to damage the nerve. The muscle and skin were sutured as described above and the same postsurgical care procedures were followed. Cuff removal was performed on day 4 after implantation.

\section{Behavioral test}

\section{Paw withdrawal thresholds}

The testing chamber consisted of a $30 \times 30 \times 30 \mathrm{~cm}$ Plexiglas box with a clear Plexiglas floor. This floor contained $0.5 \mathrm{~cm}$ diameter holes that were spaced $1.5 \mathrm{~cm}$ apart, and was positioned over a mirror tilted $45^{\circ}$ which allowed an unobstructed view of the rat paws. Animals were placed in the testing chamber and allowed to acclimatize for $30 \mathrm{~min}$ prior to testing with their cage mate. Von Frey filaments (Stoelting $\mathrm{Co}$, IL) were applied to the soft tissue of the plantar surface of the hind paw to determine the withdrawal threshold. The first filament applied corresponded to a force of $2 \mathrm{~g}$. Each filament tested was applied three times, at 3 s intervals; a paw withdrawal to any of these three applications was considered a positive response, while no response to any application was considered a negative response. If a negative response was observed, a filament exerting greater force was applied, and if a positive response was observed, a filament of lesser force was used next. A 50\% response threshold was calculated according to the response pattern observed. ${ }^{15}$ The maximum score possible was $15 \mathrm{~g}$, and the minimum was $0.25 \mathrm{~g}$.

\section{Testing after a single dose of 7-NI}

To determine if administration of 7-NI has any immediate effects on mechanical withdrawal thresholds in cuffimplanted rats, von Frey readings were taken prior to drug administration, and at 30 and $60 \mathrm{~min}$ after drug administration. 12 rats were implanted with a sciatic nerve cuff on day 0 ( $\mathrm{n}=6$ for the 7-NI treatment group; $\mathrm{n}=6$ for the vehicle group). The testing schedule was as follows: $10 \mathrm{mg} / \mathrm{kg} 7-\mathrm{NI}$ on day 2; $20 \mathrm{mg} / \mathrm{kg} 7-\mathrm{NI}$ on day 5 ; and $30 \mathrm{mg} / \mathrm{kg}$ 7-NI on day 7 post cuff-implantation. Seventy-five percent DMSO was given to the vehicle groups. Rats weighed $150-175 \mathrm{~g}$ at the time of model induction.

\section{Repeated administration of 7-NI with cuff removal}

To determine if repeated administration of 7-NI has any cumulative effects on mechanical withdrawal thresholds in the 4-day cuff removal model, rats were given $20 \mathrm{mg} / \mathrm{kg}$ 7-NI (the optimal dose as determined by the single dose experiments) daily starting on the day of cuff implantation surgery until day 4 (for a total of 5 injections). Injections were given after von Frey testing. DMSO was given to the vehicle group $(0.05 \mathrm{~mL} / 100 \mathrm{~g}$ body weight). Rats weighed $230-260 \mathrm{~g}$ at the time of model induction.

\section{Statistics}

Data from the single dose experiments were analyzed using a repeated-measures one-way analysis of variance (ANOVA) with the Bonferroni test with all pair-wise comparisons for post hoc analyses. Data from the repeated administration experiment were analyzed with a repeated-measures, two-way ANOVA (treatment and day) with Bonferroni post hoc comparisons. Analyses were performed using Prism 4.03, GraphPad Software, Inc, (San Diego, CA).

\section{Results Single dose}

Three doses of 7-nitroindazole (7-NI; 10, 20, and $30 \mathrm{mg} / \mathrm{kg}$ ) were given to rats with a permanent cuff, and paw withdrawal thresholds were measured using von Frey filaments at 30 and 60 min after drug administration. On day 2 after cuff implantation, the $10 \mathrm{mg} / \mathrm{kg}$ dose of 7-NI (IP, $\mathrm{n}=6$ ) did not have a statistically significant effect on ipsilateral (Figure 1) or contralateral (data not shown) withdrawal thresholds. Vehicle administration was without effect $(n=6$; Figure 1). On day 5, administration of $20 \mathrm{mg} / \mathrm{kg}$ 7-NI (IP, $\mathrm{n}=6$ ) significantly increased withdrawal thresholds at 60 min ( ${ }^{*} P<0.05$ compared to pre-drug values; Figure 2 ). No significant effects were observed in the contralateral paw at this dose (data not shown). Vehicle administration was without effect $(\mathrm{n}=6$; Figure 2). Administration of $30 \mathrm{mg} / \mathrm{kg}$ 7-NI (IP, $\mathrm{n}=6)$ to rats on day 7 after cuff implantation significantly increased ipsilateral withdrawal thresholds at $60 \min \left({ }^{* *} P<0.01\right.$; Figure 3$)$. No effects were observed on the contralateral side (data not shown), and the vehicle was without effect $(n=6$; Figure 3$)$. It was noted that the $30 \mathrm{mg} / \mathrm{kg}$ dose (and $75 \mathrm{mg} / \mathrm{kg}$ dose; data not shown) caused sedation and motor impairment, therefore, the $20 \mathrm{mg} / \mathrm{kg}$ dose was chosen for the repeated administration experiment.

To rule out the possibility of cumulative effects of 7-NI in this study design, a repeated-measures, one-way ANOVA was performed to compare the pre-drug baselines for each test day $(2,5$, and 7$)$. There were no differences between pre7-NI (or pre-vehicle) values. Also, unpaired $t$-tests comparing 


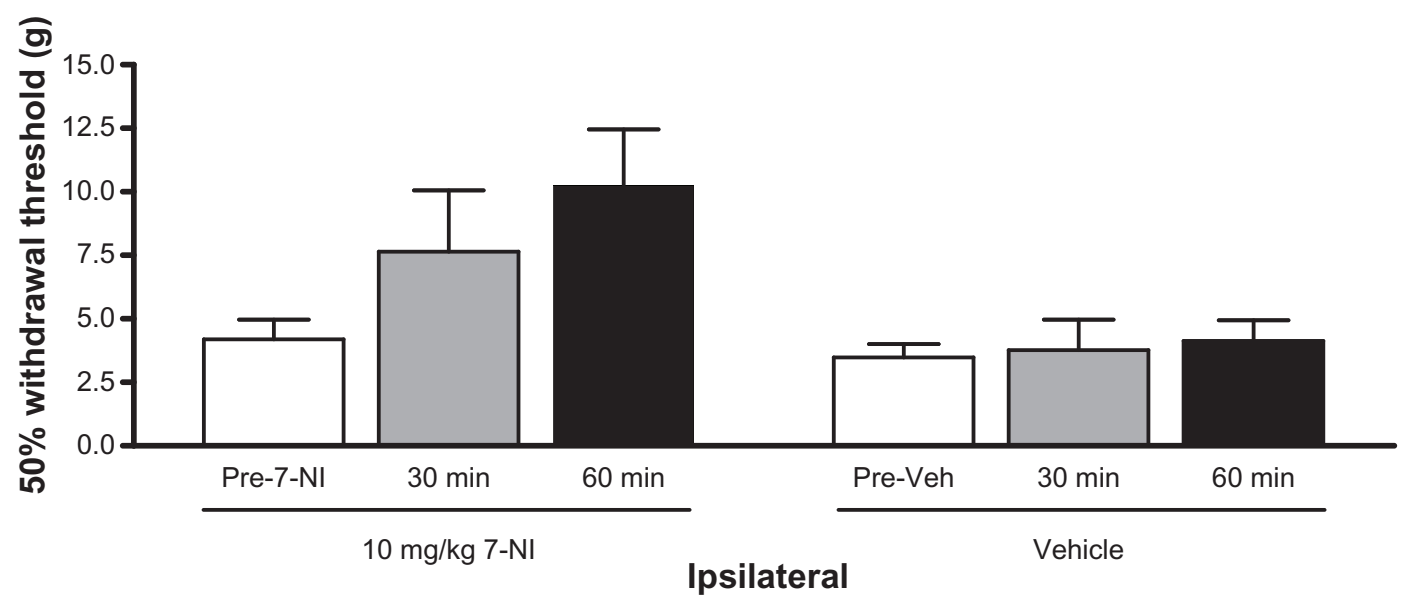

Figure I Single dose administration of 7-nitroindazole $(7-\mathrm{Nl} ; 10 \mathrm{mg} / \mathrm{kg} ; \mathrm{IP}, \mathrm{n}=6)$ to rats with a sciatic nerve cuff did not have an effect on the ipsilateral paw withdrawal thresholds at $30 \mathrm{~min}$ and $60 \mathrm{~min}$ after injection. Vehicle administration also did not have an effect at $30 \mathrm{~min}$ or $60 \mathrm{~min}(\mathrm{n}=6$ ). Testing was done on day 2 after cuff implantation.

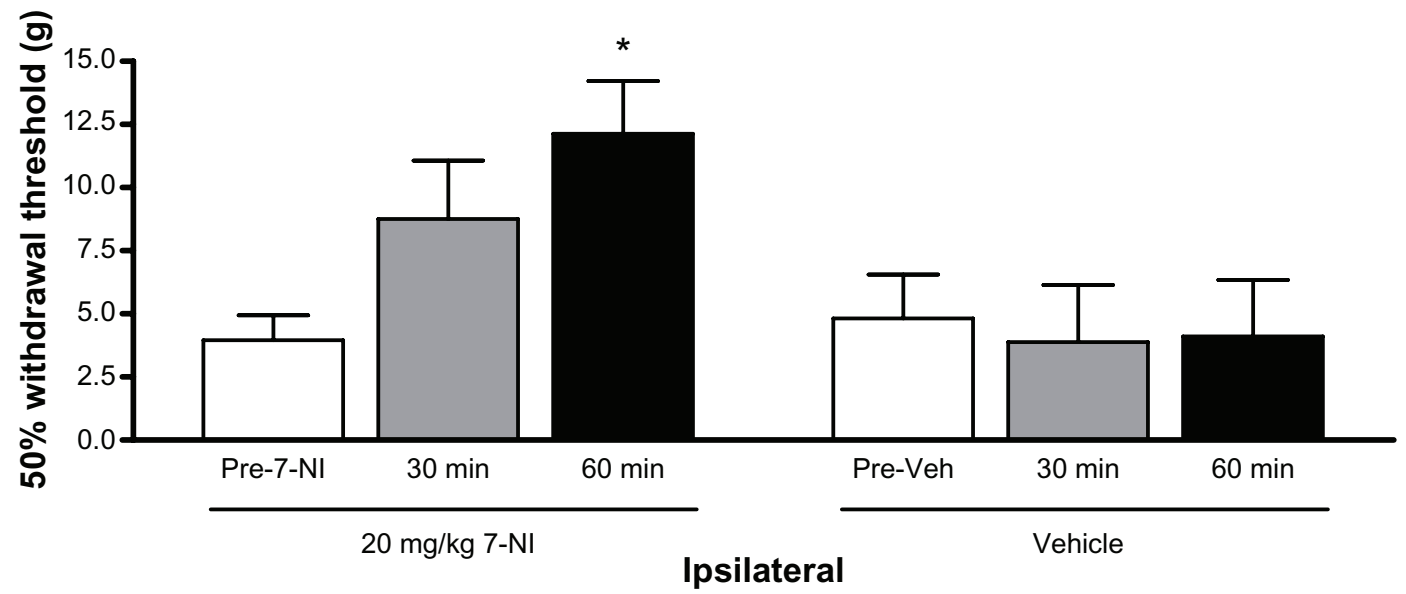

Figure 2 Single dose administration of 7-nitroindazole $(7-\mathrm{Nl} ; 20 \mathrm{mg} / \mathrm{kg} ; \mathrm{IP}, \mathrm{n}=6)$ to rats with a sciatic nerve cuff (day 5) significantly increased ipsilateral paw withdrawal thresholds at $60 \mathrm{~min}$ ( ${ }^{*} \mathrm{P}<0.05$ compared to pre-drug values). Vehicle administration did not affect ipsilateral paw withdrawal thresholds at 30 min or 60 min ( $\mathrm{n}=6$ ).

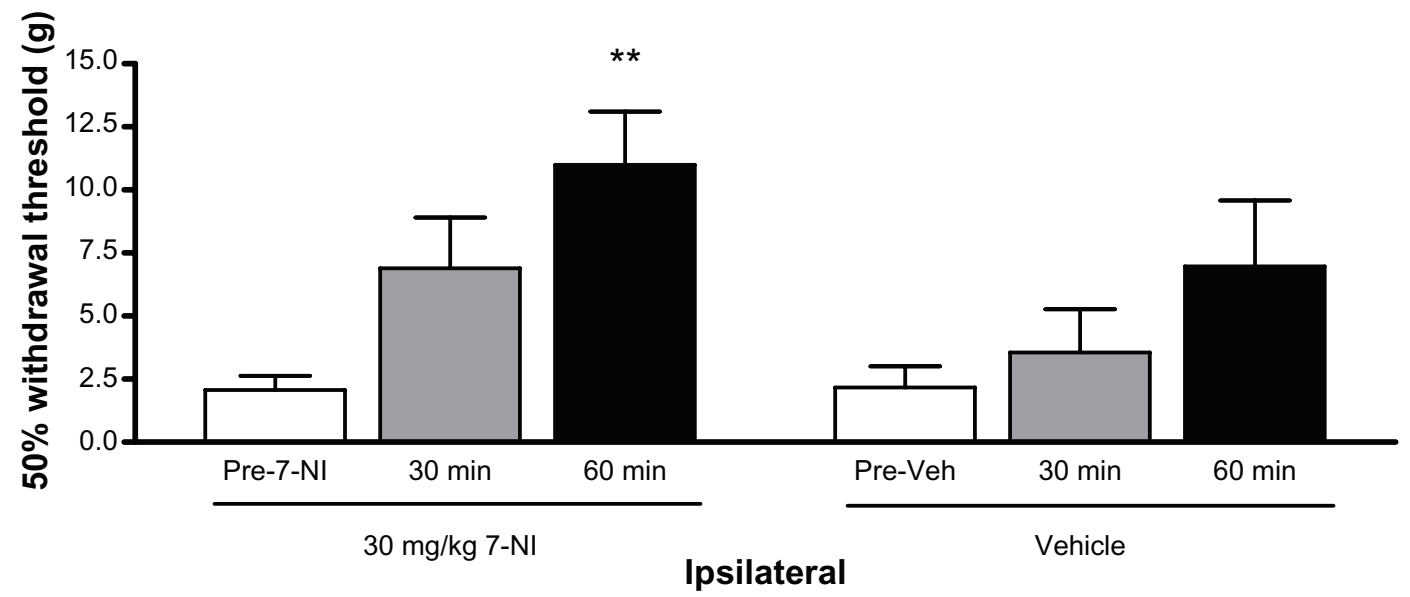

Figure 3 Single dose administration of 7-nitroindazole (7-NI; $30 \mathrm{mg} / \mathrm{kg} ; \mathrm{IP}, \mathrm{n}=6)$ to rats with a sciatic nerve cuff (day 7) significantly increased ipsilateral paw withdrawal thresholds at $60 \mathrm{~min}$ (**P $<0.01$ compared to pre-drug values). Vehicle administration did not affect ipsilateral paw withdrawal thresholds at 30 min or 60 min ( $=6$ ). 
pre-7-NI versus pre-vehicle baselines were run for each test day, and no differences were found.

\section{Repeated administration and cuff removal}

In order to determine if repeated 7-NI administration would have an effect on long-term withdrawal thresholds, rats were implanted with a sciatic nerve cuff that was removed on day 4 . Rats were given 7-NI or vehicle on days 0 to 4 . Previous studies from this laboratory have shown that there is a partial recovery with a 4-day cuff compared to a permanently implanted cuff. There were no differences in withdrawal thresholds between rats given 7 -NI $(20 \mathrm{mg} / \mathrm{kg}, \mathrm{IP}, \mathrm{n}=5)$ or vehicle $(n=5)$ on any of the days tested, over the 24-day observation period (Figure 4).

\section{Discussion}

The objective of this study was to determine the effect of the inhibition of neuronal nitric oxide synthase (nNOS), the enzyme responsible for the generation of the neurotransmitter nitric oxide in the nervous system, in a model of peripheral neuropathy. The effect of the selective nNOS inhibitor 7-nitroindazole (7-NI) was determined in the sciatic cuff model of neuropathic pain. 7-NI increased paw withdrawal thresholds at $60 \mathrm{~min}$ after administration, in a dose-dependent manner. Therefore, nNOS inhibition had an analgesic effect in this model. The effect of repeated 7-NI administration on the development of the model was also tested when the

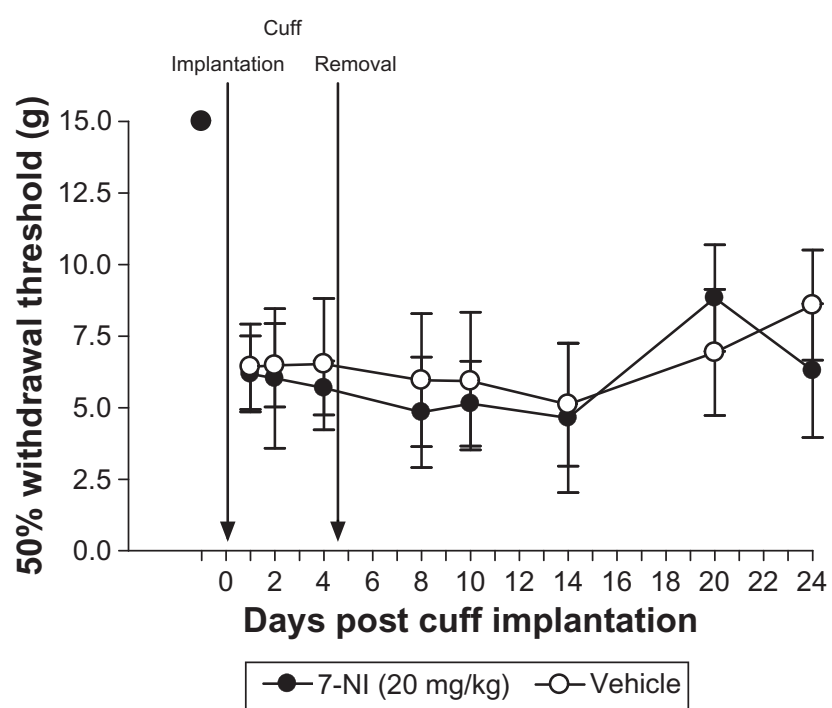

Figure 4 Rats were implanted with a sciatic nerve cuff on day 0 , and the cuff was removed on day 4. Rats were given either 7-nitroindazole (7-NI; $20 \mathrm{mg} / \mathrm{kg} ; \mathrm{IP}, \mathrm{n}=5$; closed circles) or vehicle ( $n=5$; open circles) on days 0 to 4 . There were no differences in mechanical withdrawal thresholds between the two groups on any of the days tested. cuff was removed on day 4 . In previous studies (data not shown), it was shown that cuff removal on day 4 causes partial recovery of the model after several weeks. Therefore, 7-NI was given starting immediately after cuff implantation and continued daily until cuff removal on day 4 , to determine if recovery would be accelerated or enhanced. Since no effect was observed on model development or progression, it is concluded that 7-NI did not have a preemptive or cumulative effect in this model.

The effects of single dose 7-NI observed here are in agreement with previous studies of NOS inhibition after nerve injury. The nonselective NOS inhibitor $\mathrm{N}^{\omega}$-nitro-L-arginine methyl ester (L-NAME) attenuated thermal hyperalgesia for $2 \mathrm{~h}$ when given intrathecally to rats with chronic constriction injury (CCI model; loose ligation) of the sciatic nerve. ${ }^{16}$ In the L5/L6 spinal nerve ligation model, IP L-NAME decreased mechanical hyperalgesia, cold allodynia, and signs of ongoing pain. ${ }^{17}$ In a rat model of spinal cord ischemia, L-NAME, and the selective nNOS inhibitors 6-NI (6-nitroindazole) and 7-NI given IP decreased the vocalization threshold in response to mechanical stimulation of the skin innervated by the injured spinal cord segment. ${ }^{10} 7-\mathrm{NI}$ administered by lumbar puncture to rats with sciatic nerve transection also decreased mechanical hyperalgesia and allodynia. ${ }^{12}$ This study also showed nerve-injured rats had increased expression of nNOS in the spinal cord as shown by immunohistochemistry, real-time polymerase chain reaction (PCR) and immunoblotting. In the CCI model, 10 and $30 \mathrm{mg} / \mathrm{kg}$ 7-NI, IP, but not $3 \mathrm{mg} / \mathrm{kg}$, were effective in decreasing mechanical allodynia, thermal hyperalgesia, and cold allodynia. ${ }^{13}$ The conclusion of each of these studies is that the production of nitric oxide is involved in the maintenance of pain-like behaviors following nerve injury.

Studies on the effects of repeated treatment with NOS inhibitors are scarce. A study that also used the sciatic-cuff model tested the effect of intrathecal L-NAME on heat hyperalgesia and cold allodynia when given prior to model induction and daily until day $4 .{ }^{18} \mathrm{~L}-\mathrm{NAME}$ decreased thermal sensitivity for up to 30 days post-cuff compared to controls. Although the experimental designs of this study and the present study are very similar, the use of a nonselective NOS inhibitor and the measurement of thermal sensitivity are two key differences that may account for the conflicting results. Another study used the L5/L6 spinal nerve ligation model, and mechanical allodynia was assessed using von Frey filament stimulation according to the same methods used in the present study. ${ }^{19}$ They found that a single IP L-NAME 
injection given immediately before model induction reduces mechanical allodynia for at least 14 days (the specific nNOS inhibitor LY 457963 did not have a preemptive analgesic effect). However, the preemptive effect of L-NAME was not reversible with L-arginine administration. Therefore the authors conclude that this effect is not due to NOS inhibition. ${ }^{19}$ The conclusion that NOS/nNOS inhibition is not involved in the development of the model may be in accord with the present study. However, these authors also report that the immediate analgesic (30 min to $2 \mathrm{~h}$ ) effect of L-NAME is also not reversible by L-arginine, and therefore this effect is not likely due to nNOS inhibition either. ${ }^{19}$ They suggest that L-NAME may have additional mechanisms of action that may account for its analgesic effects (immediate and preemptive).

In summary, the effectiveness of the selective nNOS inhibitor 7-NI in reducing allodynia within $60 \mathrm{~min}$ indicates that nNOS activity is involved in the steady-state model of neuropathic pain. That early and repeated 7-NI administration was without a cumulative effect suggests that nNOS activity may not be critical to the development of long-term mechanical hypersensitivity in this model of neuropathic pain.

\section{Acknowledgments}

This work was supported by a grant from McMaster University.

\section{Disclosure}

The authors report no conflicts of interest in this work.

\section{References}

1. Treede RD, Jensen TS, Campbell JN, et al. Neuropathic pain: redefinition and a grading system for clinical and research purposes. Neurology. 2008;70(18):1630-1635.

2. Meller ST, Gebhart GF. Nitric oxide (NO) and nociceptive processing in the spinal cord. Pain. 1993;52(2):127-136.

3. Freire MA, Guimaraes JS, Leal WG, Pereira A. Pain modulation by nitric oxide in the spinal cord. Front Neurosci. 2009;3(2):175-181.
4. Miclescu A, Gordh T. Nitric oxide and pain: 'Something old, something new'. Acta Anaesthesiol Scan. 2009;53(9):1107-1120.

5. Schmidtko A, Tegeder I, Geisslinger G. No NO, no pain? The role of nitric oxide and cGMP in spinal pain processing. Trends Neurosci. 2009;32(6):339-346.

6. Cizkova D, Lukacova N, Marsala M, Marsala J. Neuropathic pain is associated with alterations of nitric oxide synthase immunoreactivity and catalytic activity in dorsal root ganglia and spinal dorsal horn. Brain Res Bull. 2002;58(2):161-171.

7. Levy D, Zochodne DW. Local nitric oxide synthase activity in a model of neuropathic pain. Eur J Neurosci. 1998;10(5):1846-1855.

8. Hokfelt T, Ceccatelli S, Gustafsson L, et al. Plasticity of NO synthase expression in the nervous and endocrine systems. Neuropharmacology. 1994;33(11):1221-1227.

9. Wiesenfeld-Hallin Z, Hao JX, Xu XJ, Hokfelt T. Nitric oxide mediates ongoing discharges in dorsal root ganglion cells after peripheral nerve injury. J Neurophysiol. 1993;70(6):2350-2353.

10. Hao JX, Xu XJ. Treatment of a chronic allodynia-like response in spinally injured rats: effects of systemically administered nitric oxide synthase inhibitors. Pain. 1996;66(2-3):313-319.

11. Salter M, Strijbos PJ, Neale S, Duffy C, Follenfant RL, Garthwaite J. The nitric oxide-cyclic GMP pathway is required for nociceptive signalling at specific loci within the somatosensory pathway. Neuroscience. 1996;73(3):649-655.

12. Chacur M, Matos RJ, Alves AS, et al. Participation of neuronal nitric oxide synthase in experimental neuropathic pain induced by sciatic nerve transection. Braz J Med Biol Res. 2010;43(4):367-376.

13. Naik AK, Tandan SK, Kumar D, Dudhgaonkar SP. Nitric oxide and its modulators in chronic constriction injury-induced neuropathic pain in rats. Eur J Pharmacol. 2006;530(1-2):59-69.

14. Mosconi T, Kruger L. Fixed-diameter polyethylene cuffs applied to the rat sciatic nerve induce a painful neuropathy: ultrastructural morphometric analysis of axonal alterations. Pain. 1996;64(1):37-57.

15. Chaplan SR, Bach FW, Pogrel JW, Chung JM, Yaksh TL. Quantitative assessment of tactile allodynia in the rat paw. J Neurosci Meth. 1994;53(1):55-63.

16. Meller ST, Pechman PS, Gebhart GF, Maves TJ. Nitric oxide mediates the thermal hyperalgesia produced in a model of neuropathic pain in the rat. Neuroscience. 1992;50(1):7-10.

17. Yoon YW, Sung B, Chung JM. Nitric oxide mediates behavioral signs of neuropathic pain in an experimental rat model. Neuroreport. 1998;9(3):367-372.

18. Lui PW, Lee CH. Preemptive effects of intrathecal cyclooxygenase inhibitor or nitric oxide synthase inhibitor on thermal hypersensitivity following peripheral nerve injury. Life Sci. 2004;75(21):2527-2538.

19. Lee DH, Singh JP, Lodge D. Experiments with nitric oxide synthase inhibitors in spinal nerve ligated rats provide no evidence of a role for nitric oxide in neuropathic mechanical allodynia. Neurosci Lett. 2005;385(3):179-183.
Journal of Pain Research

\section{Publish your work in this journal}

The Journal of Pain Research is an international, peer-reviewed, open access, online journal that welcomes laboratory and clinical findings in the fields of pain research and the prevention and management of pain. Original research, reviews, symposium reports, hypothesis formation and commentaries are all considered for publication.

\section{Dovepress}

The manuscript management system is completely online and includes a very quick and fair peer-review system, which is all easy to use. Visit http://www.dovepress.com/testimonials.php to read real quotes from published authors. 